\title{
ALGUNAS REFLEXIONES SOBRE \\ LA LEY SÁENZ PEÑA Y LA PRIMERA \\ EXPERIENCIA DEMOCRÁTICA
}

LUIS ALBERTO ROMERO ${ }^{1}$

De acuerdo con el conocimiento común, la Ley Sáenz Peña estableció el sufragio universal, secreto, obligatorio, por padrón militar y con representación de mayoría y primera minoría. Todo ello fundó en la Argentina la moderna democracia. El triunfo radical en 1916, en la primera elección presidencial bajo la nueva ley, terminó de definir ese sentido fundador. Con el tiempo, distintos relatos la convirtieron en el origen, ya sea de lo bueno o de lo malo de la política democrática argentina.

Los historiadores han ido revisando esta idea, y relativizando las novedades de la ley. En este volumen, Luciano de Privitellio se pregunta qué fue exactamente lo que la ley cambió. En otro texto explicó la gradualidad de los cambios en las prácticas electorales. Luego de este prolijo trabajo deconstructivo colectivo, quizás algo quede en pie de la vieja idea: el conjunto, la suma de todos estos precedentes en una ley, y la voluntad política puesta por Sáenz Peña para transformarla en fundante de una nueva manera de votar.

La historia electoral no agota la explica- ción del impacto de la ley, que se sancionó en un momento singular de la Argentina. El contexto social, político y cultural de principios de siglo y de las décadas siguientes ayuda a entender la significación que se le atribuyó, y a comprender los sentidos en que la política democrática se desarrolló a partir de la ley. En este breve ensayo exploraré ese contexto, señalaré las opciones seguidas por la nueva política democrática -bastante distintas de las intenciones de los autores de la ley- y los conflictos de los que la democracia de Sáenz Peña fue parte. Me limitaré a la primera experiencia democrática, entre 1916 y 1955, aunque no será difícil imaginar ecos más recientes de aquellos debates y conflictos.

\section{Contexto}

En primer lugar, la ley de la democracia política llegó cuando ya estaba en marcha el largo proceso de democratización de la sociedad. Me refiero al uso de este término en el siglo XIX, por ejemplo en Tocqueville. La sociedad se rehacía por la

\footnotetext{
${ }^{1}$ Luis Alberto Romero es Investigador del CONICET y Profesor de la Universidad de Buenos Aires.
} 
llegada masiva de inmigrantes, a quienes el país dio empleo, educación y oportunidades de ascenso. Integración, movilidad y perfiles de clase poco definidos fueron las características de la nueva sociedad, en la que habitualmente, en algún sentido, los hijos estaban mejor que sus padres. Es posible registrar ese impulso a lo largo de varias décadas, quizás hasta los años sesenta. Por otra parte esta democratización comenzó a redefinir el papel de los grupos dirigentes. La antigua frase de Artigas «nadie es más que nadie», tan adecuada para la sociedad rioplatense de principios del siglo XIX, adquirió una renovada significación y comenzó a definir un ánimo democrático e igualitario, contestatario de cualquier prestigio establecido, que con el tiempo erosionó a las elites tradicionales.

La ley electoral, que con su «Quiera el pueblo votar» imperativamente llamaba a la ciudadanía, encontró buena respuesta en un terreno preparado por la democratización social, y más específicamente, por la consolidada actividad asociativa. Con Leandro Gutiérrez encontramos en esas prácticas, como las de las sociedades de fomento, una de las claves del aprendizaje práctico de la ciudadanía: interesarse por las cuestiones públicas, discutir, crear consensos, gestionar ante las autoridades. Para los vecinos, fue fácil pasar del fomentismo a los nuevos comités barriales, que la extensión del sufragio y la creación de las máquinas partidarias hizo necesa- rios. También fue un clima propicio para que se afirmara el modelo de ciudadano consciente, al que la ley interpelaba.

La ley formó parte del proceso de nacionalización encarado por el Estado nacional. Fue un proceso arduo, porque el Estado no sólo debía trabajar sobre contingentes sociales ya asentados en el territorio sino también sobre inmigrantes recién llegados. Un salteño y un hijo de italianos debían ser hechos argentinos. Ciudadanizarlos fue parte del esfuerzo de nacionalizarlos, al que concurrieron otros grandes instrumentos jurídicos, como las leyes de educación y de servicio militar.

El Estado quería hacer a los argentinos, y los inmigrantes tenían el desafío de hacerse argentinos. No debían necesariamente renunciar a su otra pertenencia nacional. La nacionalización legal no se desarrolló mucho, pero en cambio fue común la participación en la vida pública, y también la integración cultural, por vías sorprendentes, como la que estudió Adolfo Prieto a propósito de los centros nativistas, concurridos por inmigrantes que al efecto se vestían de gauchos. Al Estado le quedó otra tarea ardua: construir la Argentina en el imaginario social, su historia, su territorio, su población y sociedad, a menudo unidos en el difuso concepto de raza.

En esta construcción, inicialmente a cargo de las elites intelectuales y estatales, comenzó a arraigar la disidencia. Lilia 
Ana Bertoni ha estudiado el pasaje en las elites dirigentes de una fase de nacionalismo pluralista, convivial y cosmopolita, que convocaba a todos los que estuvieran dispuestos a vivir bajo la ley común, a otra fase de afirmación de una identidad nacional homogénea y singular, una argentinidad que equiparara al país con otros, por entonces potentes, que lucían con orgulloso la suya. El propósito de unidad que impulsaba esta idea se rompió, paradójicamente, por la falta de consenso acerca de su definición. La argentinidad se estaba forjando demasiado a la vista para que los artificios propios de esta construcción fueran convincentes para todos. No lo eran ni el hispanismo, ni el criollismo, ni la lengua, ni la raza blanca, ni el crisol de razas: todas esas propuestas fueron fuente de disputas e inquinas. Las querellas terminaron trascendiendo el campo de la elite y se instalaron en una sociedad todavía inestable, que canalizó otros conflictos en términos identitarios, y aún sigue haciéndolo.

En una sociedad dinámica y cambiante, como lo era la argentina de las primeras décadas del siglo XX, las disputas por la nacionalidad ponían en juego algo que la Ley Sáenz Peña había colocado en el centro de las luchas políticas: el "pueblo", la fuente de soberanía. Un objeto por naturaleza indefinido y mudo, a la espera de definición y voceros. Quien lograra interpelarlo de manera convincente, y con- vertirse en su vocero autorizado tenía la llave del poder, tanto en la clave electoral y democrática como en otras claves que se fueron dibujando.

En clave electoral, en el terreno definido por la Ley Sáenz Peña, fue el radicalismo, partido y movimiento a la vez, quien avanzó por ese camino, proclamando que la causa radical era la causa nacional y que su misión era la regeneración de la nación y la derrota del «régimen». Unas décadas después el peronismo siguió por ese camino, con más éxito aún que el radicalismo, y hasta llegó a institucionalizar la identificación del movimiento con la nación, y a sus enemigos con la llamada antipatria. Nunca fue una tarea fácil ni sencilla. Yrigoyen debió luchar palmo a palmo, dentro y fuera de su partido, para conservar la franquicia de lo nacional y lo popular. Entre 1930 y 1945 no faltaron intentos, pero en una sociedad polarizada ideológicamente, nadie encontró la fórmula ganadora. En 1945 Perón logró desmontar esa polarización y construir otra en la que la mayoría reconoció, en él y en su movimiento, al pueblo y a la nación.

Es sabido que Perón no construyó su movimiento sólo con ciudadanos sufragantes sino con instituciones de peso a la hora de definir el poder. Desde principios de siglo dos grandes instituciones -la Iglesia católica y el Ejército- intervinieron en el debate sobre la nacionalidad y construyeron definiciones esenciales que les asignaban 
un lugar privilegiado. El Ejército la fundó en el territorio, cuya custodia le correspondía, y en los ciudadanos soldados del Servicio Militar Obligatorio, imbuidos de subordinación y valor. La Iglesia por su parte afirmó la identidad católica de la nación argentina. Ambas instituciones, a su modo, se proclamaron voceros de la nación y definieron a sus enemigos: en un caso, los países limítrofes amenazantes; en el otro, los no católicos o quienes adhirieran a concepciones que cuestionaran la catolicidad, desde los liberales a los comunistas. Por otro camino se construía la polaridad entre la nación y sus enemigos, ya presente en la política.

Aunque no compitieron por el carril democrático, la Iglesia y el Ejército no eran ajenos a la política. No sólo fueron poderosos grupos de interés. También desarrollaron una idea de cómo organizar el Estado y gobernarlo que resultó atractiva para aquellos grupos de la elite dejados al margen de la competencia democrática. La Iglesia universal del siglo XX, la de León XIII y Pío XI, aspiró a la fundación de una sociedad cristiana, bajo la advocación de Cristo Rey. En ese contexto, desarrolló un modelo de Estado capaz de organizar e integrar los distintos cuerpos sociales, regular sus conflictos y atender preferentemente a los pobres. Era un modelo de Estado no republicano, fundado en lo que de manera desafiante llamaban "democracia cristiana», y una respuesta a lo que, en los mismos círculos, se llamaba la «cuestión social». El Ejército se preocupó principalmente por la «hipótesis de conflicto armado"; para el caso, se requería autarquía económica, unidad interior y mando unificado. En ese sentido, hizo una contribución muy importante al desarrollo en sectores estratégicos, como la aeronáutica, el petróleo o el acero, y formó calificados contingentes de funcionarios estatales. Por otra parte, entre su oficialidad se desarrolló una mirada tecnocrática y una crítica a los conflictos propios de la política democrática, que según afirmaban, conspiraban en contra de la unidad. Por esa vía cuestionaron las instituciones republicanas de gobierno y la Constitución, a las que antepusieron los llamados intereses superiores de la nación.

Nada de esto remitía a la Ley Sáenz Peña. Por el contrario, era una alternativa, un camino diferente para organizar el gobierno del Estado. Pero no era ajeno a una de las preocupaciones que inspiran la ley: el desafío que implicaba la integración a la política de sectores cada vez más amplios. Otra preocupación vinculó también a los reformistas políticos y a los intelectuales de estas dos grandes instituciones: el crecimiento del Estado, que es el último elemento contextual que quiero evocar.

En las primeras décadas del siglo XX la tarea fundamental del Estado fue arbitrar y regular los conflictos de una sociedad cada vez más compleja, en la que los di- 
ferentes intereses se agrupaban en asociaciones corporativas, para reclamar por lo suyo. Son bien conocidos la organización y los reclamos de los trabajadores, que inicialmente cuestionaron al Estado pero luego optaron por negociar con él. También se organizaron los chacareros, los peones rurales, los médicos, los ingenieros, los empresarios industriales y los estancieros. Su propósito no fue tanto la confrontación recíproca, como el reclamo para que el Estado estableciera las reglas del juego, y eventualmente concediera alguna franquicia, como por ejemplo un arancel o una exención. Las funciones del Estado y el reclamo de los intereses crecieron a pasos parejos, y después de 1930 ambos se ubicaron en un nivel sustancialmente más alto. Tal como había advertido a principios del siglo XX Durkheim, el sufragio universal y los partidos no alcanzaban para representar adecuadamente estos intereses, que necesitaban dialogar directamente con quien tomaba las decisiones. Gobernar el Estado para atender a esta tarea de regulación fue una alternativa para la que el Ejército y la Iglesia ofrecían fórmulas diferentes, y eventualmente más adecuados, que el sistema de elecciones y partidos construido a partir de la Ley Sáenz Peña. Más aún cuando, en los años 30 , ambas instituciones comenzaron a imbricarse y a articular sus discursos.

\section{Conflictos}

En este escenario, cuya vigencia puede extenderse en líneas generales hasta 1955 , se desenvolvieron dos líneas de conflicto, una afirmada en los imaginarios y otra en los intereses.

En los imaginarios hubo una lucha por las identidades, y particularmente por la definición y apropiación del pueblo y de la nación. Se desarrolló en «tono sostenido", con pasión, despliegue escénico, violencia verbal y algo de la otra. Arraigó tanto en el proceso social democrático como en el multifacético nacionalismo. La inclusión social, puntuada por la urbanización, la politización y la movilidad social, generó tensiones al sumar permanentemente nuevos aspirantes a los bienes disponibles. La pasión nacionalista, de corte unanimista, vinculada con las necesidades del Estado y también con la aspiración a la integración, se cruzó con la democracia en expansión. En esa intersección, la sacó del cauce republicano e institucional, en el que originalmente la había puesto Sáenz Peña, y la trasladó al cauce plebiscitario, donde la unanimidad se construía más fácilmente. La voluntad popular, siempre huidiza, se encarnó en líderes fundadores de movimientos que se identificaron con el pueblo y la nación, prometieron y escenificaron la inclusión y fueron ratificados con muchos votos. En el mismo gesto, estos movimientos definieron al enemigo de manera sufi- 
cientemente ambigua como para ajustar en cada coyuntura su caracterización ocasional. A quienes no pertenecían al movimiento de la nación y el pueblo se les atribuía el oscuro designio de excluir, y por eso debían ser excluidos. En la década del 30, la Iglesia y el Ejército ensayaron, por la vía no democrática, un experimento similar, en torno de la propuesta de una nación católica.

Los conflictos de identidad alrededor de lo nacional y popular se fusionaron con los conflictos políticos, se potenciaron y conformaron un clima de polarización facciosa, tan característico del yrigoyenismo como del peronismo. Identidades excluyentes hicieron imposible lo que era el corolario de la Ley Sáenz Peña: la existencia de partidos, ya fuera de ideas o de intereses organizados y procesados, que discutieran, se alternaran pacíficamente y construyeran, conscientemente o no, políticas de largo plazo.

El otro conflicto fue menos espectacular y apasionado pero con similares posibilidades corrosivas para la convivencia política: la disputa de los grupos de interés, preocupados por influir en las decisiones del Estado que conllevaban algún reparto de beneficios. Gobernar un Estado asediado por exigentes pedigüeños, cuya intervención era requerida de manera creciente, comenzó a parecer incompatible con la democracia política. Lo era tanto por las disputas facciosas que conllevaba como por la atribuida ineficacia para seleccionar administradores estatales adecuados para funciones crecientemente complejas. A la vez, la democracia electoral resultó inadecuada para quienes querían acceder a lugares del Estado desde donde se podía actuar en favor de un determinado interés.

Los partidarios de un Estado con unidad de comando, y los partidarios de un lobismo al margen de la competencia electoral tenían propósitos contrarios, pero sus caminos se encontraron en una propuesta similar: un Estado orgánico, que incluyera bajo su tutela a todos los grupos de interés, cuidados y armonizados por un gobierno fuerte y capaz a la vez. Un modelo ideal para las fuerzas armadas, para las elites a quienes el sufragio universal marginaba y para la Iglesia, que podía suministrar a esta forma de Estado un libreto legitimado en Santo Tomás. Concebido como panacea de la conflictividad y como alternativa para la Ley Sáenz Peña, este Estado encerraba su propia carga de conflictos, cuando la disputa de intereses escapara al control del gobierno y convirtiera al Estado en un campo de combate y a la vez en un botín.

La Ley Sáenz Peña recogió diversas tendencias de la Argentina de comienzos del siglo XX, se potenció con ellas, y aspiró a convertirse en la clave de la convivencia política. Su mayor capital convivencial se encontraba en la combinación de la legi- 
timidad del sufragio y el orden mesurado de las instituciones republicanas. Pero las cosas fueron diferentes. La democratización marchó por el camino que le trazaba el nacionalismo, y el Estado lo hizo por el sendero de la corporación de intereses y la unidad de creencia y de mando. Ambas tendencias se conjugaron en 1945 cuando, con el advenimiento del peronismo, llegó a su punto culminante esta primera experiencia democrática nacional y popular, ordenada, pero profundamente faccionalizada y amenazada por los conflictos de interés alojados en su seno.
Al final de esta primera experiencia democrática, la Argentina carecía de los consensos básicos para sustentar un Estado gobernado democráticamente. Es sabido que en las décadas siguientes estos conflictos se agudizaron. También, que en 1983 se desarrolló el intento más fuerte de construir una democracia institucional. El camino seguido desde 1989 hasta la actualidad recuerda, cada vez más, el derrotero de la primera experiencia democrática.

\section{Registro bibliográfico \\ ROMERO, LUIS ALBERTO}

«Algunas reflexiones sobre la Ley Sáenz Peña y la primera experiencia democrática», en: ESTUDIOS SOCIALES, revista universitaria semestral, año XXII, No 43, Santa Fe, Argentina, Universidad Nacional del Litoral, segundo semestre, 2012, pp. 267-273. 